\title{
Bioprosthetic pulmonary valve replacement: Contemporary analysis of a large, single-center series of 170 cases
}

\author{
Xu-Jun Chen, MD, PhD, ${ }^{\mathrm{a}, \mathrm{b}}$ P. Brian Smith, MD, MPH, MHS, ${ }^{\mathrm{c}} \mathrm{James}$ Jaggers, MD, ${ }^{\mathrm{b}}$ and \\ Andrew J. Lodge, $\mathrm{MD}^{\mathrm{b}}$
}

Objective: The present study was designed to compare stented porcine and bovine pericardial valves used for pulmonary valve replacement to better define valve performance and postoperative quality of life.

\begin{abstract}
Methods: A retrospective review of all patients who underwent pulmonary valve replacement with a stented bioprosthesis from 1992 to 2008 was conducted. The medical records, imaging results, and quality of life questionnaires were analyzed. Differences in reintervention by valve type were determined using Cox proportional hazards models, controlling for subject age.
\end{abstract}

\begin{abstract}
Results: A total of 170 consecutive pulmonary valve replacements ( 73 stented porcine, group 1; 97 bovine pericardial, group 2) were reviewed. No significant differences were seen in patient age or implanted valve size between the groups. Surgical mortality was $1.2 \%$. The median follow-up was 48.2 months and was longer for group 2. No significant difference was seen in the risk of reintervention by valve type (hazard ratio, 0.64; $95 \%$ confidence interval, $0.18-2.34 ; P=.51$ ). After 39 months of follow-up, pulmonary stenosis and pulmonary insufficiency that was moderate or worse were more common in patients who had undergone pulmonary valve replacement at younger than 15 years (pulmonary stenosis, $30.9 \%$ vs $10.0 \%, P=.003$; pulmonary insufficiency, $46.2 \%$ vs $3.8 \%, P<.001$ ), regardless of valve type. All patients performed well mentally and physically on the quality of life surveys.

Conclusions: The present large series of stented bioprosthetic pulmonary valve replacements has demonstrated good results, particularly in adults, at intermediate follow-up. Freedom from reintervention was similar for the porcine and pericardial valves, and our finding did not clearly demonstrate the superiority of 1 type of valve. However, the stented bioprosthetic valves were less durable in younger patients. (J Thorac Cardiovasc Surg 2013;146:1461-6)
\end{abstract}

The pulmonary valve is the least commonly replaced cardiac valve, but it can require replacement either at primary repair of a congenital cardiac defect or at reoperation. The options for pulmonary valve replacement (PVR) include mechanical, homograft, or surgically constructed polytetrafluoroethylene valves and xenograft biological valves. ${ }^{1-5}$ Despite small series showing favorable results, ${ }^{2,6}$ mechanical valves are typically not used in the pulmonary position because of the increased risk of thrombosis. Catheter-delivered stent valves have also recently been used for PVR. ${ }^{7}$ Based on observations from our practice and a review of the published data, ${ }^{1-7}$ stented bioprosthetic valves might be the most durable pulmonary

\footnotetext{
From the Department of Cardiothoracic Surgery, ${ }^{\text {a }}$ Shanghai Tongji Hospital, Tongji University, Shanghai, China; Division of Thoracic and Cardiovascular Surgery, ${ }^{\text {b }}$ Department of Surgery, and Department of Pediatrics, ${ }^{\mathrm{c}}$ Duke University Medical Center, Durham, NC.

Disclosures: Authors have nothing to disclose with regard to commercial support.

Received for publication May 1, 2012; revisions received Aug 10, 2012; accepted for publication Sept 13, 2012; available ahead of print Nov 5, 2012.

Address for reprints: Andrew J. Lodge, MD, Division of Cardiovascular and Thoracic Surgery, Department of Surgery, Duke University Medical Center, Box 3851, Durham, NC 27710 (E-mail: andrew.lodge@dm.duke.edu). $0022-5223 / \$ 36.00$

Copyright (c) 2013 by The American Association for Thoracic Surgery http://dx.doi.org/10.1016/j.jtcvs.2012.09.081
}

valve substitute for older children and adults. They have become the valve substitute of choice at our institution in absence of the need for complex reconstruction of the right ventricular outflow tract.

However, biological valves are susceptible to degeneration, and patients might require 1 or more reoperations. Although several previous studies ${ }^{5,8-10}$ have examined the results of bioprosthetic PVR with various prosthetic valves, only 1 other large series of PVR patients comparing the performance of the available stented bioprostheses has been published. ${ }^{5}$ The present study was designed to compare the outcomes and patient quality of life after PVR using a bovine pericardial or stented porcine bioprosthetic valve. These data will also help to provide a standard with which to compare the results of percutaneously placed pulmonary stent valves, which have recently been introduced to clinical practice.

\section{METHODS}

We identified all patients who had undergone stented bioprosthetic PVR at Duke University Medical Center from 1992 to 2008. Each patient received either a bovine pericardial (Perimount; Carpentier-Edwards, Edwards Lifesciences, Irvine, Calif) or stented porcine xenograft (Hancock II; Medtronic, Minneapolis, Minn, or Biocor or Epic; St. Jude Medical, St. Paul, Minn) valve. The medical records were reviewed for demographic and clinical information and all follow-up imaging results. Pulmonary stenosis (PS) and pulmonary insufficiency (PI) were graded using the 


$$
\begin{aligned}
& \text { Abbreviations and Acronyms } \\
& \text { PI = pulmonary insufficiency } \\
& \text { PS }=\text { pulmonary stenosis } \\
& \text { PVR }=\text { pulmonary valve replacement } \\
& \text { RV }=\text { right ventricular } \\
& \text { TOF }=\text { tetralogy of Fallot }
\end{aligned}
$$

following numerical scale: 0 , none; 1 , trace or trivial; 2 , mild; 3 , moderate; and 4 , severe, according to the findings from the most recent echocardiogram. The patients were contacted and asked to complete the short form health survey questionnaire ( 36 item, version 2 for adults and 10-item short form for children) to evaluate their health and quality of life after surgery. ${ }^{11,12}$ The Duke University institutional review board approved the present study. Informed consent was waived for the review of medical records but obtained from patients contacted for the purposes of completing the questionnaire.

In each patient, PVR was performed during normothermic or mildly hypothermic cardiopulmonary bypass. The proximal pulmonary artery was opened through a longitudinal incision. The bioprosthesis was implanted while the heart was perfused and beating, unless a residual intracardiac shunt was present. In the latter case, a brief period of induced ventricular fibrillation or cardioplegic arrest was used to repair the defect, after which the PVR was completed. The pulmonary artery incision was extended slightly onto the right ventricle or through a previous outflow tract patch, as needed, to permit implantation of the appropriate-size valve prosthesis. An effort was made to implant the largest size prosthetic valve that would reasonably fit within the outflow tract. The valve was implanted at or near the orthotopic position with a running polypropylene suture. Once the valve was implanted, the right ventricular outflow tract was usually augmented with a patch of polytetrafluoroethylene, unless the pulmonary artery could be closed primarily over the valve. The use of this technique allowed the implantation of the optimal size valve.

Data collection and statistical analyses conformed to the guidelines for reporting mortality and morbidity after cardiac valve interventions. ${ }^{13}$ Categorical variables are expressed as frequencies and percentages. Continuous variables are expressed as the mean \pm standard deviation or median and range. The Wilcoxon rank sum and Fisher exact test, as appropriate, were used to compare the demographic variables. Differences in reintervention by valve type were determined using Cox proportional hazards models, controlling for subject age ( $<15$ vs $\geq 15$ years). Survival analyses were performed using the Kaplan-Meier actuarial method.

\section{RESULTS \\ Demographics}

A total of 161 consecutive patients underwent 170 PVR operations with stented bioprostheses ( 73 porcine valves, group 1 ; and 97 bovine pericardial valves, group 2; Table 1). No significant difference was seen between the 2 groups in either age at PVR or implanted valve size. Follow-up was longer for the group 2 patients ( $61 \pm 36$ months vs $33 \pm 31$ months, $P<.001)$. The most common primary diagnosis was tetralogy of Fallot (TOF) followed by pulmonary atresia with or without a ventricular septal defect (Table 2).

\section{Valve Function}

Follow-up echocardiography was available for $81 \%$ of the patients. On their most recent echocardiograms, a greater percentage of group 2 patients had moderate to severe PS than group 1 patients $(27.0 \%$ vs $8.2 \%$, $P=.007)$, but the mean echocardiographic grade of PS was similar between the 2 groups $(P=.89)$. A significantly greater percentage of group 2 patients had at least moderate PI compared with the group 1 patients $(26.4 \%$ vs $13.3 \%$, $P=.083$ ), and the mean echocardiographic grade of PI was significantly greater in group 2 than in group 1 $(P<.001)$. However, the echocardiographic follow-up duration was shorter in group 1 than in group 2 (31.7 vs 55.7 months, $P<.001$ ).

Age at PVR significantly affected valve performance. Age younger than 15 years at PVR was associated with a greater incidence of both PS $(P=.003)$ and PI $(P<.001)$ at the last follow-up examination (Table 3). Of the children younger than 15 years of age, $31 \%$ had at least moderate PS and $46.2 \%$ had at least moderate PI compared with $10.0 \%$ and $3.8 \%$, respectively, of older patients (Table $3)$. The median follow-up was 50 months for the younger group and 34 months for the older group $(P=.047)$.

\section{Freedom From Reintervention}

Freedom from reintervention, either catheter or surgical, for all patients is shown in Figure 1. The percentage of all valve replacements that were free from reintervention at 1,5 , and 10 years was $99 \%$ (142/144), 94\% (66/70), and $36 \%(9 / 25)$, respectively. A total 18 total reinterventions were required in 16 patients, including 6 transcatheter balloon valvuloplasties and 12 reoperations. All but 1 of the patients requiring reintervention was younger than 15 years at PVR. The indications for reintervention included PS in 12, PI in 8, right ventricular (RV) dilatation in $4, \mathrm{RV}$ dysfunction in 6 , tricuspid regurgitation in 2 , and endocarditis in 2 . The average interval from PVR to reintervention was 72 months, including 2 early reoperations for endocarditis at 2 and 6 months. Pulmonary arterioplasty or stent placement was attempted in 10 of the 18 cases at reintervention.

Controlling for patient age at surgery, no significant difference was seen in the risk of reintervention by valve type (hazard ratio, $0.64 ; 95 \%$ confidence interval, 0.18 2.34; $P=.51$; Figure 2). Controlling for both patient age and valve size $(\mathrm{mm})$ made no differences in the effect of valve type on the risk of reintervention. Age younger than 15 years at surgery was a significant risk factor for reintervention (hazard ratio, 19.54; 95\% confidence interval, 2.56$149.19 ; P=.004$; Figure 3 ). Of the patients younger than 15 years old, $65 \%$ received a pericardial valve. Controlling for valve type, age younger than 15 years at surgery was a risk factor for reintervention $(P<.001)$. Valve durability was excellent in older patients. In the 1 patient aged 15 years or older at primary PVR, the indication for repeat PVR was prosthetic valve endocarditis, not structural valve deterioration. 
TABLE 1. Demographics

\begin{tabular}{lccr}
\hline \multicolumn{1}{c}{ Variable } & $\begin{array}{c}\text { Porcine valve } \\
(\mathbf{n}=\mathbf{7 3})\end{array}$ & $\begin{array}{c}\text { Pericardial valve } \\
(\mathbf{n}=\mathbf{9 7})\end{array}$ & $\boldsymbol{P}$ value \\
\hline Males (n) & $48(65.7 \%)$ & $58(59.8 \%)$ & .42 \\
Age (y) & & & .31 \\
$\quad$ Median & 19 & 16 & \\
$\quad$ Range & $4-66$ & $0.5-72$ & \\
Age $<15$ y (n) & $25(34.3 \%)$ & $44(45.4 \%)$ & .16 \\
Valve size (mm) & & & .77 \\
$\quad$ Median & 25 & 25 & \\
$\quad$ Range & $21-29$ & $19-29$ & \\
Follow-up (mo) & & & \\
$\quad$ Median & 24 & 58 & \\
$\quad$ Range & $0.03-135$ & $1-181$ & \\
\hline
\end{tabular}

\section{Surgical Mortality and Late Death}

Two deaths occurred within 30 days of surgery $(2 / 170$, $1.2 \%$ ). A 12 -year-old girl with a history of multiple cardiac operations, including atrioventricular septal defect repair, mitral valve replacement, and a Ross-Konno procedure, underwent revision of her RV to pulmonary atrial conduit with a stented bioprosthetic valve and redo mitral valve replacement. She died on postoperative day 1 of cardiac arrest. The second early death was a 9-year-old girl who had undergone repair of TOF during infancy. She underwent an apparently uncomplicated PVR, had an uneventful postoperative course, and was discharged to home on postoperative day 7. She died on postoperative day 27 of an unknown cause. Two additional late deaths occurred at 5.6 years and almost 9 years postoperatively.

\section{QRS Duration}

In addition to PS and PI, a prolonged QRS interval has been suggested as an indication for PVR in patients with TOF. Some have suggested that PVR might stabilize or result in improvement in the QRS duration. Among all patients with a preoperative QRS interval greater than $150 \mathrm{~ms}$, no significant change was seen in the QRS duration (168 ms vs $166 \mathrm{~ms}, P=.49$ ) at a mean follow-up of 43 months after PVR. Only those patients who had

TABLE 2. Principal diagnosis for all patients

\begin{tabular}{lc}
\hline \multicolumn{1}{c}{ Variable } & Patients, $\mathbf{n}$ \\
\hline Tetralogy of Fallot variants & $86(53.4 \%)$ \\
Pulmonary atresia with or without VSD & $24(14.9 \%)$ \\
Congenital pulmonary stenosis & $16(9.9 \%)$ \\
After Ross procedure & $13(8.1 \%)$ \\
Truncus arteriosus & $6(3.7 \%)$ \\
Transposition of great arteries & $5(3.1 \%)$ \\
Double outlet right ventricle & $4(2.5 \%)$ \\
Pulmonary valve dysplasia & $2(1.2 \%)$ \\
Other & $5(3.1 \%)$ \\
\hline
\end{tabular}

VSD, Ventricular septal defect.
TABLE 3. Valve function of stented bioprosthetic pulmonary valves

\begin{tabular}{lcrr}
\hline \multicolumn{1}{c}{ Variable } & $\begin{array}{c}\text { Age }<\mathbf{1 5} \mathbf{y} \\
(\mathbf{n}=\mathbf{6 9})\end{array}$ & $\begin{array}{c}\text { Age } \geq \mathbf{1 5} \mathbf{y} \\
(\mathbf{n}=\mathbf{1 0 1})\end{array}$ & $\boldsymbol{P}$ value \\
\hline Moderate or greater PS (\%) & $30.9(17 / 55)$ & $10(8 / 80)$ & .003 \\
Moderate or greater PI (\%) & $46.2(24 / 52)$ & $3.8(3 / 80)$ & $<.001$ \\
\hline PI, Pulmonic insufficiency; $P S$, pulmonic stenosis. & &
\end{tabular}

a preoperative electrocardiogram within 30 days of surgery and a postoperative electrocardiogram at least 60 days after surgery were considered $(\mathrm{n}=37)$.

\section{Quality of Life}

The quality of life after PVR was evaluated using standardized assessment tools. The rate of return of the quality of life surveys was relatively low. Survey results were available for 34 adults and 17 children younger than 15 years old. Adult patients performed well from both a mental and a physical health perspective, with no differences compared with the general population (Figure 4). As a group, they were not limited in their ability to perform everyday physical activities. The survey results for the children showed that they fared just as well as their peers from a psychosocial standpoint. However, a trend was seen toward lower scores in the physical health domain (Figure 5).

\section{DISCUSSION}

It has been reported that PVR, when performed after repair of various congenital heart defects, including TOF, can normalize the RV dimensions, improve both RV and left ventricular contractility, decrease the incidence of symptomatic arrhythmias, improve exercise capacity, and reverse clinical symptoms. ${ }^{5,14-17}$ The ideal pulmonary valve substitute has not yet been clearly defined. Compared with mechanical, homograft, and polytetrafluoroethylene valves, ${ }^{1-5}$ stented bioprosthetic valves in the pulmonary

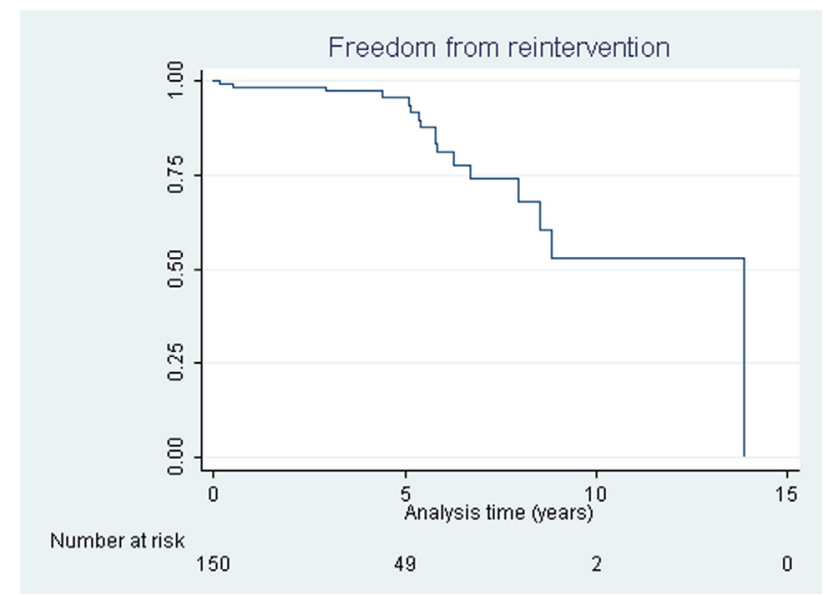

FIGURE 1. Kaplan-Meier actuarial freedom from reintervention in patients who underwent stented bioprosthetic pulmonary valve replacement. 


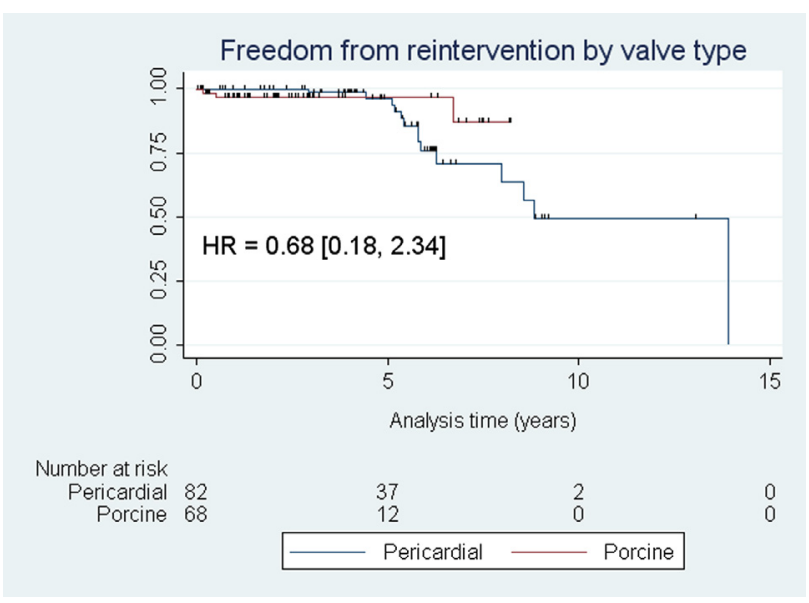

FIGURE 2. Comparison of Kaplan-Meier actuarial freedom from reintervention in patients stratified by valve type. No significant difference was found in overall reintervention rate between groups. $H R$, Hazard ratio.

valve position have been shown to be a better option in some recent reports. ${ }^{5,10,14-17}$ However, these reports have mostly been small series, and none have directly compared the results of the different available types of stented bioprosthetic valves. We sought to further elucidate this issue by reporting 1 of the largest PVR series using these valves.

In our present study, the surgical mortality of PVR with stented bioprosthetic valves was $1.2 \%$. Only 2 late deaths occurred. A total of 18 reinterventions were required in 16 patients after mean follow-up of 48 months, suggesting that PVR with a stented bioprosthetic valve can be considered a good PVR option. Although previous reports, 10,14-17 of PVR with stented bioprosthetic valves have been

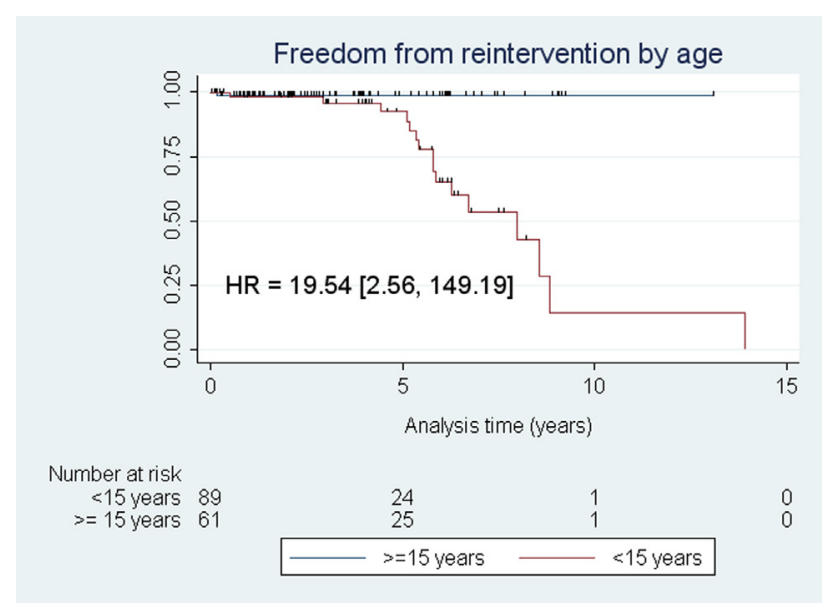

FIGURE 3. Comparison of Kaplan-Meier actuarial freedom from reintervention in patients younger than 15 years and those 15 years old or older at pulmonary valve replacement. The re-intervention rate was significantly greater for the younger group. $H R$, Hazard ratio.

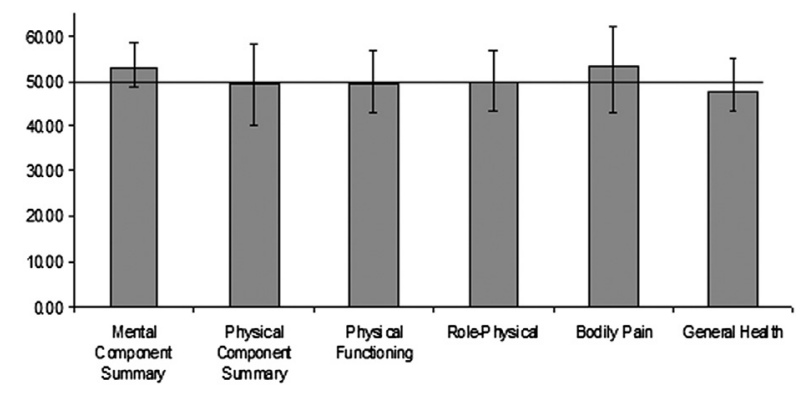

FIGURE 4. Graph showing results of 36-item, version 2, short form health survey completed by adult patients $(\mathrm{n}=34)$. Horizontal line represents median value for normal population.

published, all but 2 included substantially fewer patients or patients with both stented and nonstented valves, or both.

In the present study, we sought to compare the outcomes with stented porcine (group 1) and bovine pericardial (group 2) valves. Although the duration of follow-up for the group 2 patients was longer than that for the group 1 patients, the freedom from reintervention was similar for both groups. The results of our study were not consistent with the results from other recent studies that suggested that bovine pericardial valves are more durable than porcine valves when used for PVR. ${ }^{5,14}$ One study by Fiore and colleagues, ${ }^{14}$ who compared 3 biologic valve types-pulmonary homograft, bovine pericardial, and porcine-concluded that a stented porcine valve is more prone to dysfunction than a bovine pericardial valve $(9 / 47$ porcine valves, $19 \%$, vs $1 / 18$ bovine pericardial valves, $5.5 \%$ ). Our study did not confirm this finding. An important difference between the study by Fiore and colleagues ${ }^{14}$ and our study was that their study only included 18 patients with bovine pericardial valves, but our series included a significantly larger number of patients in whom both of these prostheses were implanted, with a more convincing statistical outcome. Another more recent study by Lee and colleagues, ${ }^{5}$ who evaluated the durability of 3 bioprosthetic valve types in the pulmonary position, demonstrated that no significant difference was present in the freedom from valve failure and dysfunction between the stented porcine

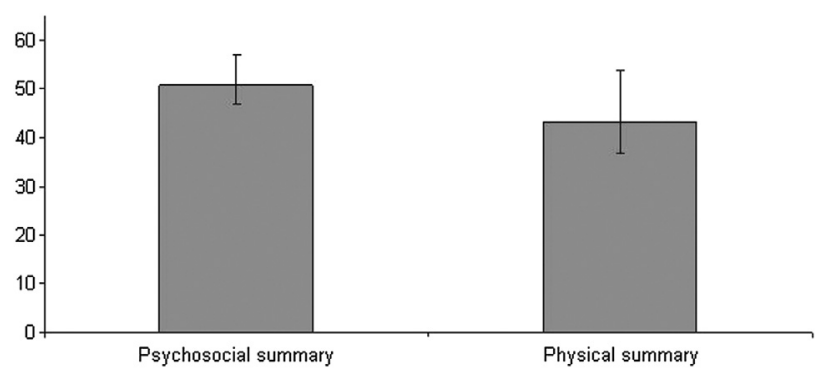

FIGURE 5. Graph showing results of 10 -item, short form health survey for children completed by pediatric patients $(\mathrm{n}=17)$. Horizontal line represents median value for normal population. 
$(\mathrm{n}=105)$ and bovine pericardial $(\mathrm{n}=53)$ valves after mean follow-up of $7.3 \pm 2.9$ years. It is possible that the differences we observed between the pericardial and porcine valves were related to the follow-up duration, because the patients with pericardial valves had a longer follow-up time in our series but the patients with porcine valves had a longer follow-up time in the study by Lee and colleagues. ${ }^{5}$ Moreover, more patients had bovine pericardial valves $(\mathrm{n}=97)$ in our series than in the study by Lee and colleagues $^{5}(\mathrm{n}=53)$. Unlike in our series, Lee and colleagues ${ }^{5}$ did not document the statistical similarity in patient age and valve size between stented porcine and bovine pericardial valves, making it somewhat more difficult to interpret their results.

Our data suggest that patient age at surgery, not the stented bioprosthetic valve type, is the principal determinant of valve performance. A recent study of children undergoing PVR by Zubairi and colleagues, ${ }^{10}$ also found that younger age at PVR was a significant risk factor for late bioprosthetic valve failure. However, their study included only 87 total patients and only 16 with stented porcine valves. The study by Lee and colleagues ${ }^{5}$ also demonstrated that freedom from both prosthetic valve failure and dysfunction at 10 years was $6.2 \% \pm 4.2 \%$ for patients younger than 10 years and $12.6 \% \pm 10.8 \%$ for patients older than 10 years $(P<.001)$. Other studies ${ }^{14-18}$ have also demonstrated that young age at valve replacement is associated with an increased risk of prosthetic valve failure and dysfunction. In the present study, we sought to clarify this and to separate the effect of valve type from age. The large number of patients included in our study allowed for this comparison. When comparing the groups and controlling for patient age, no difference was found in reintervention by valve type. In contrast, when controlling for valve type, age younger than 15 years was a risk factor for later reintervention. Our data have shown that the outcomes for PVR in those aged 15 years or older are excellent, with only 1 patient requiring late reintervention thus far. Therefore, consideration should be given to the size of the stented bioprosthesis that can be implanted in a child. If a larger valve cannot be implanted, it might be reasonable to consider implanting a valved conduit, such as a homograft or bovine jugular vein graft. This would allow for later placement of a percutaneous stent valve. Satisfactory results have been reported in studies of valvein-valve for a failed bioprosthesis in the pulmonary position, ${ }^{19,20}$ although the follow-up duration has been limited to date.

Importantly, although it might be fairly common current practice to place oversize stented valves in younger patients, a recent study by Chen and colleagues ${ }^{21}$ has called this practice into question. In their study, a greater indexed prosthetic valve size was a risk factor for accelerated structural valve deterioration in smaller patients. Although our study did not include an analysis stratified by the indexed valve size, it is clear that in younger patients, even the smallest available stented bioprosthetic valves $(19 \mathrm{~mm})$ will be oversize, because a $19-\mathrm{mm}$ pulmonary valve is the normal valve diameter for a patient with a body surface area greater than $1 \mathrm{~m}^{2}$. Therefore, our data support the findings of Chen and colleagues, ${ }^{21}$ and we would agree that oversizing a stented bioprosthesis in a smaller, younger patient will not be beneficial.

A prolonged QRS duration has been strongly associated with RV function and prognosis in patients with TOF and, in some studies, has been shown to be reduced postoperatively after PVR. In 1 recent study, ${ }^{22}$ a longer postoperative QRS duration or a failure to shorten the postoperative QRS duration was significantly associated with an adverse outcome. Although the electrocardiographic data were limited in our study, we also found that in patients with a preoperative QRS duration greater than $150 \mathrm{~ms}$, there was no significant change in QRS duration (168 ms vs $166 \mathrm{~ms}$ ) at mean interval of 43 months after surgery. These data support the concept that PVR might stabilize the QRS duration, although they do not support the assertion that PVR effectively shortens the QRS duration.

Limited data have been reported regarding the quality of life assessment for patients with repaired TOF. ${ }^{23}$ The quality of life achieved by PVR has been receiving more attention in the recent published data of aortic valve replacement with mechanical versus biologic prostheses ${ }^{24}$ mitral valve replacement or repair, ${ }^{25}$ and tricuspid valve replacement. ${ }^{26}$ As yet, little or no data are available regarding the quality of life of patients after PVR. The present study, to our knowledge, is also the largest series documenting the quality of life of patients after implantation of a stented bioprosthesis in the pulmonary valve position. Although the survey return was suboptimal, quality of life after PVR was measured in both children and adults in our study and showed results very similar to those observed in the general population from both a mental and a physical health perspective. There might have been a slight trend toward lower physical health scores in the younger children surveyed, perhaps reflecting a pediatric population that is more ill than the adults. Overall, however, these data suggest that PVR with a stented bioprosthetic valve results in a satisfactory subjective result from the patient's perspective.

In conclusion, the present series of a large number of stented bioprosthetic pulmonary valves indicates that these valves provide a durable pulmonary valve substitute and good quality of life, with most patients free from significant PS or PI at intermediate follow-up. Freedom from reintervention was similar for porcine and pericardial valves, and the present large study did not clearly demonstrate the superiority of 1 valve type. The greater overall reintervention rate and amount of PS and PI in the pericardial group might have reflected the longer follow-up time. 
Age younger than 15 years at PVR was associated with increased PS, PI, and reintervention. Valve performance was excellent in patients aged 15 years or older at PVR. Valve dysfunction in older patients is more likely to be due to stenosis, which might be amenable to catheter intervention in place of reoperation. In older adolescents and adult patients undergoing PVR, stented bioprosthetic valves should be considered a durable option. In smaller children, other options should be considered. These data also provide a useful standard by which to compare stent-mounted valves in the future.

The present study was limited by its retrospective, singlecenter design. Follow-up data were not available for all patients who underwent PVR and the follow-up duration differed between the valve types. The choice of bioprosthetic valve was at the discretion of the surgeon. To truly determine a difference between stented pericardial and porcine valves, a randomized multicenter trial would likely be required. Also, no preoperative quality of life surveys for comparison and no standard criteria for reintervention were available.

\section{References}

1. Discigil B, Dearani JA, Puga FJ, Schaff HV, Hagler DJ, Warnes CA, et al. Late pulmonary valve replacement after repair of tetralogy of Fallot. J Thorac Cardiovasc Surg. 2001;121:344-51.

2. Rosti L, Murzi B, Colli AM, Festa P, Redaelli S, Havelova L, et al. Mechanical valves in the pulmonary position: a reappraisal. J Thorac Cardiovasc Surg. 1998; 115:1074-9.

3. Quintessenza JA, Jacobs JP, Morell VO, Giroud JM, Boucek RJ. Initial experience with a bicuspid polytetrafluoroethylene pulmonary valve in 41 children and adults: a new option for right ventricular outflow tract reconstruction. Ann Thorac Surg. 2005;79:924-31.

4. Oosterhof T, Meijboom FJ, Vliegen HW, Hazekamp MG, Zwinderman AH, Bouma BJ, et al. Long-term follow-up of homograft function after pulmonary valve replacement in patients with tetralogy of Fallot. Eur Heart J. 2006;27: 1478-84.

5. Lee C, Park CS, Lee CH, Kwak JG, Kim SJ, Shim WS, et al. Durability of bioprosthetic valves in the pulmonary position: long-term follow-up of 181 implants in patients with congenital heart disease. J Thorac Cardiovasc Surg. 2011;142:351-8.

6. Waterbolk TW, Hoendermis ES, den Hamer IJ, Ebels T. Pulmonary valve replacement with a mechanical prosthesis: promising results of 28 procedures in patients with congenital heart disease. Eur J Cardiothorac Surg. 2006;30:28-32.

7. Webb JG, Wood DA, Ye J, Gurvitch R, Masson JB, Rodés-Cabau J, et al. Transcatheter valve-in-valve implantation for failed bioprosthetic heart valves. Circulation. 2010;121:1848-57.

8. Kwak JG, Lee JR, Kim WH, Kim YJ. Mid-term results of the Hancock II valve and Carpentier-Edward Perimount valve in the pulmonary portion in congenital heart disease. Heart Lung Circ. 2010;19:243-6.
9. Fukada J, Morishita K, Komatsu K, Abe T. Influence of pulmonic position on durability of bioprosthetic heart valves. Ann Thorac Surg. 1997;64:1678-80.

10. Zubairi R, Malik S, Jaquiss RD, Imamura M, Gossett J, Morrow WR. Risk factors for prosthesis failure in pulmonary valve replacement. Ann Thorac Surg. 2011; 91:561-5.

11. Georgiadou P, Kontodima P, Sbarouni E, Karavolias GK, Smirli A, Xanthos T, et al. Long-term quality of life improvement after transcatheter aortic valve implantation. Am Heart J. 2011;162:232-7.

12. Zhang L, Fos PJ, Johnson WD, Kamali V, Cox RG, Zuniga MA, et al. Body mass index and health related quality of life in elementary school children: a pilot study. Health Qual Life Outcomes. 2008;6:77.

13. Akins CW, Miller DC, Turina MI, Kouchoukos NT, Blackstone EH, Grunkemeier GL, et al. Guidelines for reporting mortality and morbidity after cardiac valve interventions. Ann Thorac Surg. 2008;85:1490-5.

14. Fiore AC, Rodefeld M, Turrentine M, Vijay P, Reynolds T, Standeven J, et al. Pulmonary valve replacement: a comparison of three biological valves. Ann Thorac Surg. 2008;85:1712-8.

15. Lindsey CW, Parks WJ, Kogon BE, Sallee D III, Mahle WT. Pulmonary valve replacement after tetralogy of Fallot repair in preadolescent patients. Ann Thorac Surg. 2010;89:147-51.

16. Gengsakul A, Harris L, Bradley TJ, Webb GD, Williams WG, Siu SC, et al. The impact of pulmonary valve replacement after tetralogy of Fallot repair: a matched comparison. Eur J Cardiothorac Surg. 2007;32:462-8.

17. Cheung EW, Wong WH, Cheung YF. Meta-analysis of pulmonary valve replacement after operative repair of tetralogy of Fallot. Am J Cardiol. 2010;106:552-7.

18. Caldarone CA, McCrindle BW, van Arsdell GS, Coles JG, Webb G, Freedom RM, et al. Independent factors associated with longevity or prosthetic pulmonary valves and valved conduits. J Thorac Cardiovasc Surg. 2000;120: 1022-31.

19. Khambadkone S, Coats L, Taylor A, Boudjemline Y, Derrick G, Tsang V, et al. Percutaneous pulmonary valve implantation in humans: results in 59 consecutive patients. Circulation. 2005;112:1189-97.

20. Eicken A, Ewert P, Hager A, Peters B, Fratz S, Kuehne T, et al. Percutaneous pulmonary valve implantation: two-centre experience with transcatheter valvein-valve implantation for failed bioprosthetic heart valves with more than 100 patients. Eur Heart J. 2011;32:1260-5.

21. Chen PC, Sager MS, Zurakowski D, Pigula FA, Baird CW, Mayer JE, et al. Younger age and valve oversizing are predictors of structural valve deterioration after pulmonary valve replacement in patients with tetralogy of Fallot. $J$ Thorac Cardiovasc Surg. 2012;143:352-60.

22. Scherptong RW, Hazekamp MG, Mulder BJ, Wijers O, Swenne CA, van der Wall EE, et al. Follow-up after pulmonary valve replacement in adults with tetralogy of Fallot: association between QRS duration and outcome. J Am Coll Cardiol. 2010;56:1486-92.

23. Lu JC, Cotts TB, Agarwal PP, Attili AK, Dorfman AL. Relation of right ventricular dilation, age of repair, and restrictive right ventricular physiology with patient-reported quality of life in adolescents and adults with repaired tetralogy of Fallot. Am J Cardiol. 2010;106:1798-802.

24. Aicher D, Holz A, Feldner S, Köllner V, Schäfers HJ. Quality of life after aortic valve surgery: replacement versus reconstruction. J Thorac Cardiovasc Surg. 2011;142:e19-24.

25. Jokinen JJ, Hippeläinen MJ, Pitkänen OA, Hartikainen JE. Mitral valve replacement versus repair: propensity-adjusted survival and quality-of-life analysis. Ann Thorac Surg. 2007;84:451-8.

26. Viganò G, Guidotti A, Taramasso M, Giacomini A, Alfieri O. Clinical mid-term results after tricuspid valve replacement. Interact Cardiovasc Thorac Surg. 2010; 10:709-13 